\title{
Synthesis and Characterization of New Anthracene-Based Blue Host Material
}

\author{
Ki Ho So, Hyun-Tae Park, Sung Chul Shin, Sang-Gyeong Lee, Dong Hui Lee, Kyeong-Hoon Lee, \\ Hyeong-Yun Oh, ${ }^{\ddagger}$ Soon-Ki Kwon, ${ }^{;}$and Yun-Hi Kim ${ }^{-}$ \\ Department of Chemistry and Research Institute of Natural Science, Gveongsang National University. \\ Chinju 660-701, Korea. 'E-mail, vimagsnu.ac.kr \\ tSchool of Haterial Science \& Engineering and Engineering Research Institute, Gveongsang Vational Lniversity, \\ Chinju 660-701, Korea \\ $\ddagger_{L G}$ Elite, Seoul 137-724, Korea \\ Received Mav 19, 2009, Accepted June 5, 2009
}

\begin{abstract}
We designed new anthracene-based host material to increase color purity as well as derice efficiency. The new blue host, 9,10-bis(2,4-dimethylphenyl)anthracene (BDA), has highly twisted structure and wide band gap due to ortho interaction between anthracene and introduced 2,4-dimethylphenyl substituents. BDA exhibited deep blue fluorescence in solution $\left(\lambda_{\max }=410 \mathrm{~nm}\right)$ and in solid state $\left(\lambda_{\max }=429 \mathrm{~nm}\right)$, respectively, with the wide optical band gap $(E=3.12 \mathrm{eV})$. Blue-light-emitting OLEDs using obtained host and $2 \%$ Flu-DPAN as emitter showed $8 \mathrm{~cd} / \mathrm{A}$ of high efficiency as well as high color purity [CIE coordinates $=(0.15,015)$ ].
\end{abstract}

Key Words: Blue host. Anthracene. Twisted structure. Wide band gap

\section{Introduction}

Organic electroluminescent devices (OLEDs) have been widely investigated for their applications in high efficiency. low drive voltage. large display area of full-color flat panel displays. ${ }^{1.6}$ The various device configurations. fluorescent materials. and electrode materials have been studied to improve the efficiency and stability' of the organic EL devices. ${ }^{-t}$ The guest/host systems have been demonstrated as a virtual approach to achieve high performance devices. and much work had been done in developing the guest and host materials and their combinations. ${ }^{8.11}$ Generally. the good host material is required to possess a wide energy gap. carrier transporting abilities as well as film forming abilities. The most used host materials involve di(stryl)arylene derivatives and anthracene derivatives. ${ }^{\text {l(k-11 }}$

The guest materials are required to possess high luminescent efficiency as well as the ability of accepting energy from host materials via the Foster energy transfer and/or the direct recombination via the charge trapping. ${ }^{1 Y-13}$

Recently. we reported the 2,6-disubstituted-9,10-diphenyl anthracene derivatives (2.6-DPAN derivatives) as efficient blue emitters. The new designed non-doped blue emitting materials in multilayer structure devices achieved luminescence of $3600-4500 \mathrm{~cd} / \mathrm{m}^{2}$ at $100 \mathrm{~mA} / \mathrm{cm}^{2}$ and maximum efficiency of $4.6-5.8 \mathrm{~cd} / \mathrm{A}^{14}$

In this paper. we designed new host material to increase color purity as well as device efficiency for (2.6-bis (9.9-diethyl$9 H$-fluoren-2-yl)-9,10-diphenylanthracene) (Flu-DPAN). ${ }^{14}$ The new designed host material has antluracene main unit because of the compatible ability with guest. Flu-DPAN, which had anthracene main unit. The 2.4-dimethylphenyl group which can be highly twisted to anthracene because of ortho interaction, was introduced to anthracene main unit to induce relatively wide energy gap compared with dopants. We also report the synthesis, characterization, fabrication and performance of an OLED device using new host and Flu-DPAN as blue emitting layer.

\section{Experimental}

${ }^{l} \mathrm{H}-\mathrm{NMR}$ spectra were recorded using a Bruker AM-500 spectrometer. and chemical shifts are reported in ppm units with tetramethylsilane as internal standard. FT-IR spectra were obtained with a Bomem Michelson series FT-IR spectrometer and UV-visible absorption spectra were obtained in chloroform on a Shimadzu UV-3100 spectrophotometer. Melting points were determined using an Electrothermal Mode 1307 digital analyzer. Thermal analysis was carried out on a Dupont TGA 2100 thermogravimetric analyzer in a nitrogen atmosphere at a rate of $10^{\circ} \mathrm{C} / \mathrm{min}$. The photoluninescence spectra were recorded on a Perkin-Elmer LS-50 fluorometer utilizing a lock-in amplifier system with a chopping frequency of $150 \mathrm{~Hz}$. Elemental analyses were performed by Leco Co. CHNS-932. Redox potentials of the compounds were deternined by cyclic voltanmetry (CV) using a BAS $100 \mathrm{~B}$ electrochemical analyzer with a scanning rate at 100 $\mathrm{mV} / \mathrm{s}$. The compound coated Pt disc was measured in a three electrode compartment cell with a Pt wire counter electrode and an $\mathrm{Ag} / \mathrm{AgNO}_{3}(0.1 \mathrm{M})$ reference electrode. The electrolyte was $0.1 \mathrm{M} \mathrm{Bu}_{4} \mathrm{NClO}_{4}$ solution in anhydrous acetonitrile. and the cell was purged with argon. Ferrocene was used for potential calibration (all reported potentials are referenced against $\mathrm{Ag} / \mathrm{Ag}^{+}$) and for reversibility criteria. Organic EL devices were fabricated using successive vacuum-deposition of $N . N^{\prime}$-diphen] $]$ l- $X_{N} N^{\prime}$-bis-[4-(phenyl-m-tolyl-amino)-phenyl]-

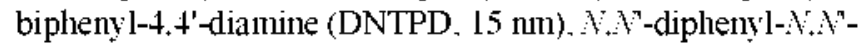
di(l-napthl)-l,I'-biphenyl-4.4'-diamine (NPD. $20 \mathrm{~nm}$ ). BDA/ (2\% Flu-DPAN) (20 nm), tris (8-quinolinolato)aluminum (III) $\left(\mathrm{Alq}_{\mathrm{s}}, 40 \mathrm{~nm}\right), \mathrm{LiF}(1 \mathrm{~nm})$, and $\mathrm{Al}$ electrode on top of the ITO 
glass substrate. The ITO glass with a sheet resistance of about $10 \Omega$ was etched for the anode electrode pattern and cleaned in ultrasonic baths of isopropyl alcohol and acetone. The overlap area of $\mathrm{Al}$ and ITO electrodes is about $4 \mathrm{~mm}^{2}$. A UV zone cleaner (Jeilight Company) was used for further cleaning before vacuum deposition of the organic materials. Vacuum deposition of the organic materials was carried out under a pressure of $2 \times 10^{-3}$ torr. The deposition rate for organic materials was about $0.1 \mathrm{~nm} / \mathrm{s}$. The evaporation rate and the thickness of the film were measured with a quartz oscillator. OLED performance was studied by measuring the currentvoltage-luminescence (I-V-L) characteristics. EL. and PL spectra at room temperature. I-V-L characteristics and CIE color coordinates were measured with a Keithley SMU238 and Spectrascan PR650. EL spectra of the devices were measured utilizing a diode array rapid analyzer system (Professional Scientific Instrument Corp.) Fluorescence spectra of the solutions in clloroform were measured using a spectrofluorimeter (Shimadzı Corp.).

Synthesis. 9,10-dibmmoanthracene: ${ }^{15}$ Bromine (17.9 g. 5.8 $\mathrm{mL}, 0.112 \mathrm{~mol}$ ) in acetic acid $(50 \mathrm{~mL})$ was added dropwise over a period of 5 minutes to a vigorously stirred suspension of anthracene $(10.0 \mathrm{~g} .0 .056 \mathrm{~mol})$ in acetic acid $(300 \mathrm{~mL})$ at room temperature. The reaction was left to stir for 30 minutes during which a canary yellow precipitate formed. Water $(300$ $\mathrm{mL}$ ) was added. the suspension left to stir for 10 minutes, then filtered and washed with a little water. The yellow solid was dried in vacuo for $2+$ hours to give the compound (17.70 g) Yield: $94 \%$. mp: $220-222{ }^{\circ} \mathrm{C},{ }^{\mathrm{J}} \mathrm{H}-\mathrm{NMR}\left(500 \mathrm{MHz}, \mathrm{CDCl}_{3}\right)$ ò $8.60(4 \mathrm{H}), 7.66(4 \mathrm{H})$.

2,4-Dimethylphenyl bononic acid: $0.075 \mathrm{~mol}$ of $\mathrm{Mg}$, catalytic amount of 1.2-dibromoethane and $50 \mathrm{~mL}$ of tetrahydrofiurane was stirred in the nitrogen atmosphere. $0.0269 \mathrm{~mol}$ of 1 -bromo2.4-dimethylphenyl was added in the solution. After the Grignard reagent was completely made, $0.0269 \mathrm{~mol}$ of triethylborate was added in the mixture. The reaction was terminated by adding of $2 \mathrm{~N} \mathrm{HCl}$ aqueous solution. The cnide product was recrystallized in the THF. Yield: $40 \% \mathrm{mp}: 197-198^{\circ} \mathrm{C}$. ${ }^{1} \mathrm{H}-\mathrm{NMR}\left(500 \mathrm{MHz} . \mathrm{CDCl}_{3}\right)$ ò $8.0-7.3$ (m. 3H), 2.5 (s, 3H). 2.1 (s. 3H), FT-IR (KBr, cm${ }^{-1}$ ): 3500 (O-H str), 3030 (aromatic C-H str), 2950 (aliphatic C-H str), 1650 (aromatic C-C str).

9,10-Bis(2,4-dimethylphenyl)anthracene: 9.10-Dibromoanthracene (1.3 g. 4 mmol) and 9.9-diethy l-9H-fluoren-2-yl-2boronic acid ( $1.4 \mathrm{~g} .9 .4 \mathrm{mmol}$ ) were mixed in THF. $10 \mathrm{~mL}$ of aqueous $\mathrm{K}_{2} \mathrm{CO}_{3} 2 \mathrm{M}$ solution was added to the mixture. Make a nitrogen stream and leave it for 40 minutes. This prevents palladium catalyst from decomposing by the oxygen in the air. (2.3 g. $2 \mathrm{mmol}$ ) of tetrakis (triphenylphosphine)palladium $\left(\operatorname{Pd}\left(\mathrm{PPh}_{3}\right)_{4}\right)$ was added in the mixture and the solution was refluxed for $24 \mathrm{~h}$. After the reaction was completed, the reaction was terminated with $2 \mathrm{~N} \mathrm{HCl}$ aqueous solution. The product was extracted with ether. The cnide product was purified by column chromatography with hexane/ethylacetate (10/1) as eluent. Yield: $50 \%$, mp: $295 \sim 296{ }^{\circ} \mathrm{C}$. ${ }^{\mathrm{H}} \mathrm{H}-\mathrm{NMR}(500 \mathrm{MHz}$. $\left.\mathrm{CDCl}_{3}\right) \delta 7.5(\mathrm{~m}, 1 \mathrm{H}), 7.3(\mathrm{~m} . \mathrm{H}), 7.2(\mathrm{~s}, 1 \mathrm{H}), 2.5(\mathrm{~s} .3 \mathrm{H}) .1 .9$ (s. $3 \mathrm{H}$ ). FT-IR $\left(\mathrm{KBr} \mathrm{cm}^{-1}\right.$ ): 3030 (aromatic C-H str). 2950 (aliphatic C-H str). 1650 (aromatic C-C str).

\section{Result and Discussion}

Scheme 1 showed the synthetic route of new host. 9.10bis(2,4-dimetlylphenyl)anthracene (BDA). The BDA was obtained by Pd-catalyzed Suzuki coupling reaction of 2.4dimethylphenyl boronic acid and 9.10-dibromoantluracene. The structure of BDA was confirmed by NMR and IR as well as Mass spectroscopy: $\mathrm{M}^{+}$value of the $\mathrm{BDA}$ was equal to the molecular weights. Theoretical calculations using Hyperchem 7.0 professional (Hy percube) were carried out to characterize the three-dimensional-structures and energy density of highest occupied molecular orbital (HOMO) and lowest unoccupied molecular orbital (LUMO) of each material by using PM3 parameterization. Figure 1 shows the threedimensional structure and HOMO. LUMO energy density of BDA and reported [2,6-bis(9,9-diethy l-9H-fluoren-2-yl)-9,10diphenylanthracene (Flu-DPAN)] derived by theoretical calculation. ${ }^{14}$ The highly twisted structure of BDA may be explained by ortho interaction between methyl group and antluracene main unit. The new designed BDA host represented relatively wide band gap compared with Flu-DPAN as expected. From the result. it is suggested that the efficient Forster energy transfer can be occurred from the new synthesized host BDA to the guest Flu-DPAN.

The thermal properties were investigated by thermal gravimetric analysis (TGA) and differential scanning calorimetry (DSC). BDA showed good themal stability with 5\% weight loss at $300^{\circ} \mathrm{C}$. (Figure 2) In DSC measurement, no crystallization exotherms or melting endotherms as well as no glass transition was noticed upon heating until $250^{\circ} \mathrm{C}$. It has been implied that BDA has noncoplanar structure with good thermal stability even though it is a low molecular weight organic compound. Stability in the anorphous state is a basic requirement for materials used in light emitting diodes. Because the heat produced from operating OLED devices can damage EL molecules and cause cracks.

The UV-Vis and photoluminescence (PL) spectra of BDA in dilute solution and photoluminescence (PL) spectnum of BDA in solid film are shown in Figure 3. The multiple absorption peaks around $393 \mathrm{~nm}$ with characteristic vibronic pattern are associated with the $\pi-\pi^{*}$ transitions of anthracene core. As expected by theoretical calculation, BDA exhibited deep blue

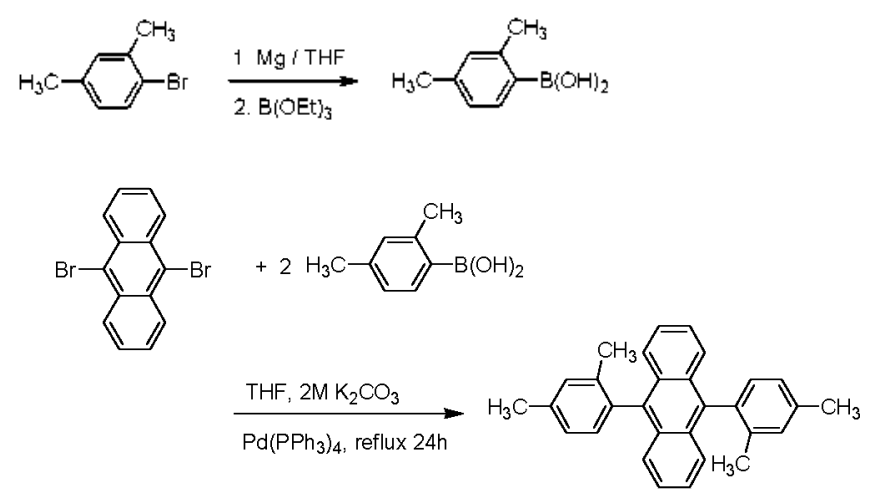

Scheme 1. Synthetic route of 9,10-bis(2,4-dimethy lphenyl anthracene. 

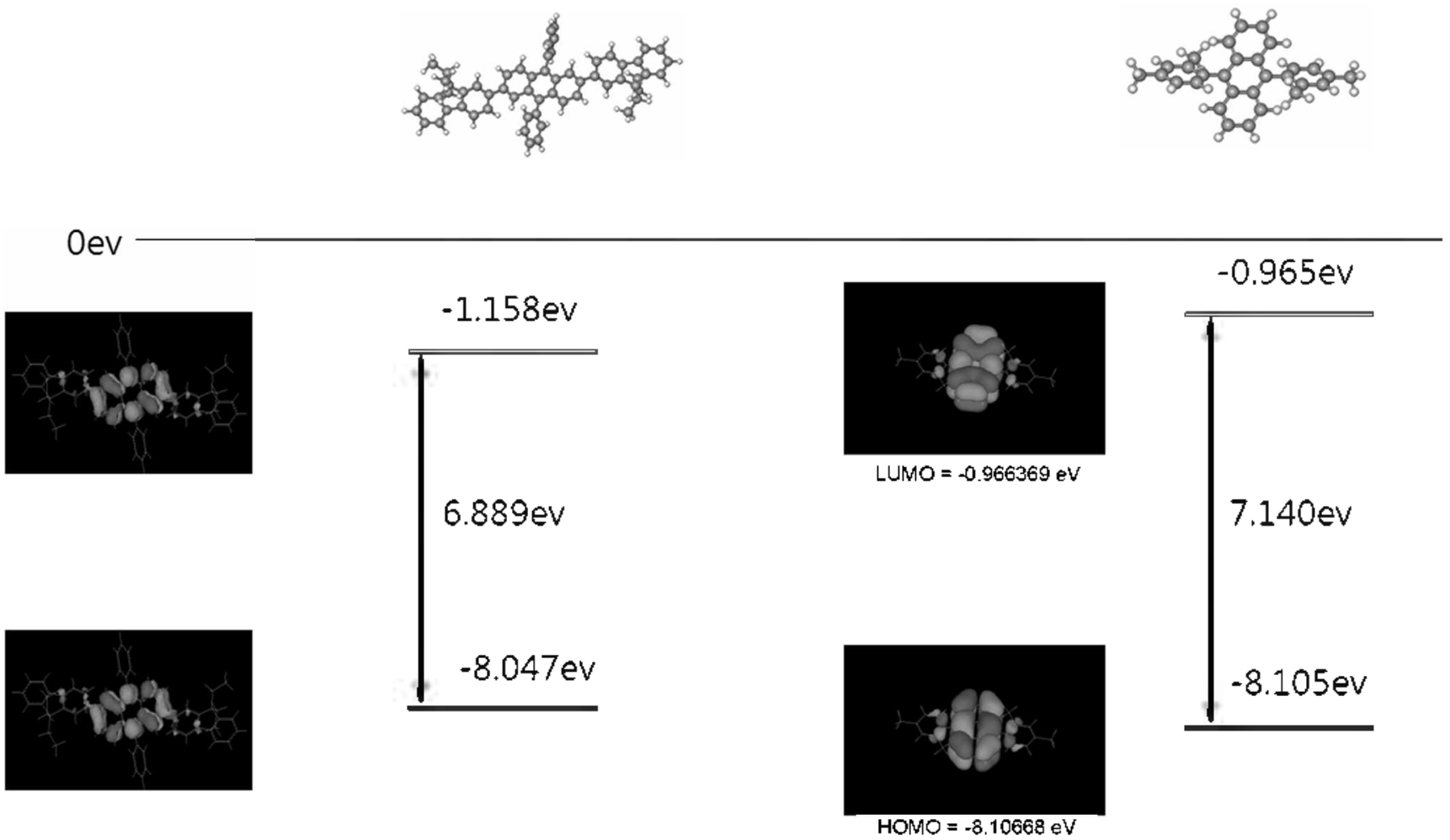

Figure 1. Three-dimensional structure and HOMO, LUMO energy density of BDA and reported [2,6-bis(9,9-diethyl-9H-fluoren-2-y])-9,10-diphenylantluracene (Flu-DPAN)].
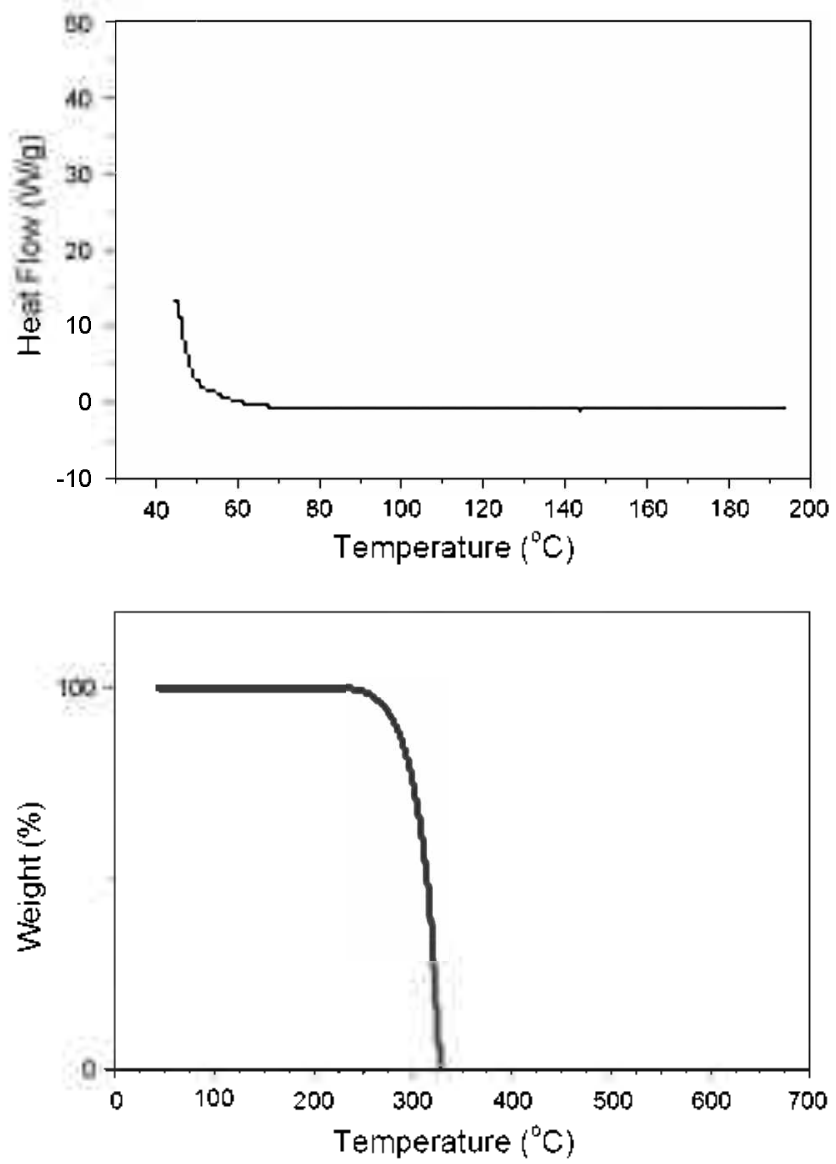

Figure 2. TGA and DSC curve of BDA. fluorescence in solution $\left(\lambda_{\text {ylici }}=410 \mathrm{~nm}\right)$ and in solid state $\left(\lambda_{\text {miax }}=\right.$ $429 \mathrm{~nm})$. respectively. The optical band gap $(E=3.12 \mathrm{eV}$ ) was calculated from absorption edge (UV edge $=400 \mathrm{~nm}$ ). The result also can be comparable with reported Flu-DPAN (UV edge = $430 \mathrm{~mm}, 2.9 \mathrm{eV}$ ). In addition. the full width at half maximum (FWHM) for both solution and solid enussion spectra are as narrow as $50 \sim 55 \mathrm{~nm}$.

Figure + shows the photoluminescence spectrum of host and UV-Vis absorption spectra of reported Flu-DPAN. From

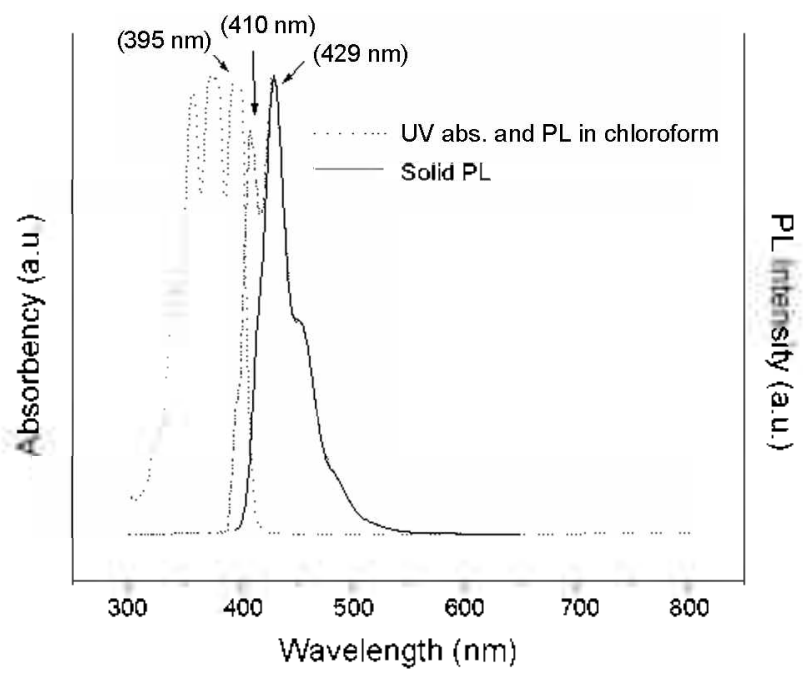

Figure 3. UV-Vis and photoluminescence (PL) spectra of BDA in dilute solution and photoluminescence (PL) spectrum of BDA in solid film. 
the spectra, it can be suggested that the efficient energy transfer can be occurred by the closed match of emission spectnum of host and absorption spectnum of guest. As expected theoretical calculation, it is suggested that the efficient Forster energy transfer can be occurred from the new sy nthesized host BDA to the guest Flu-DPAN.

The energy levels of host and guest are obtained by cyclic voltammetry (CV) measurements. Cyclic voltammetry of BDA was measured in a three electrode compartment cell with a Pt wire counter electrode and an $\mathrm{Ag} / \mathrm{AgNO}_{3}(0.1 \mathrm{M})$ reference electrode at a scan rate of $100 \mathrm{mV} / \mathrm{s}$. The electrolyte was $0.1 \mathrm{MBu} \mathrm{NClO}_{4}$ solution in anhydrous acetroniltrile, and the cell was purged with nutrogen. The oxidation peak potential of host were measured to be $E_{o x}=1.56 \mathrm{~V}$. The HOMO and LUMO level of BDA was obtained $5.96 \mathrm{eV}$ and $2.84 \mathrm{eV}$. respectively. from the calculation of oxidation peak potential and optical band gap. In general electron and hole trapping will be most favorable when the LUMO level of host is higher and HOMO level is lower than that of guest. It is demonstrated that the energy gap of BDA is much wider than that of Flu-DPAN and accord with what is required by charge

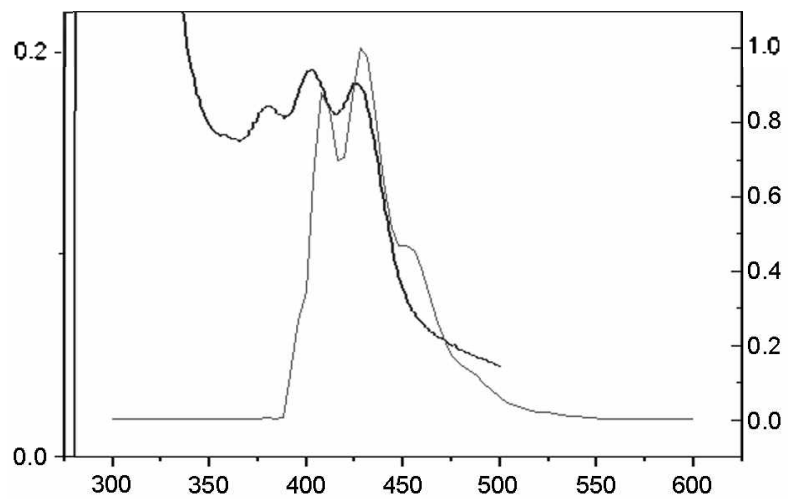

Figure 4. Photoluminescence spectrum of BDA and UV-Vis absorption spectra of reported Flu-DPAN.

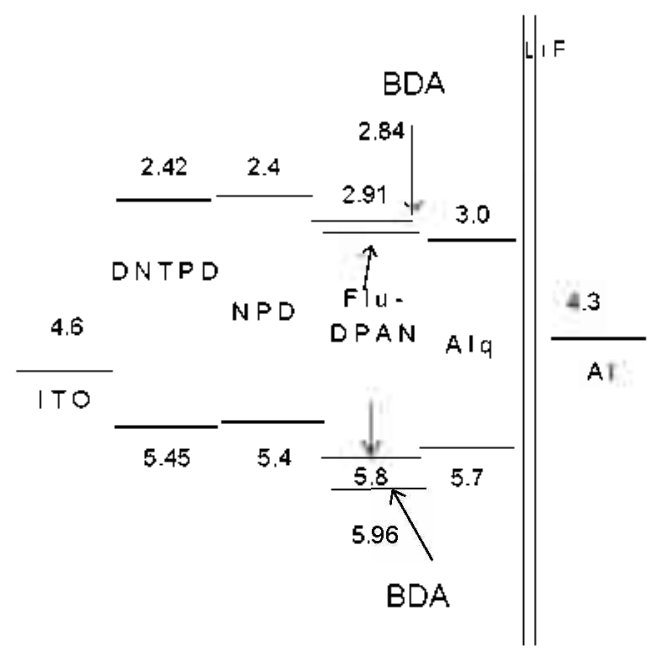

Figure 5. Energy diagram of indium tin oxide (ITO)/(DNTPD, 15

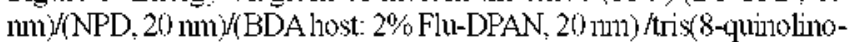
lato) aluminum (Aly3, $40 \mathrm{~nm})(\mathrm{LiF}, \mathrm{nm}) / \mathrm{Al}$. trapping. (Figure 5)

Blue-light-emitting OLEDs using BDA as host and $2 \%$ Flu-DPAN as emitter was fabricated in the configuration indium tin oxide (ITO)/(DNTPD. $15 \mathrm{lum}$ )/(NPD. $20 \mathrm{lum}) /(\mathrm{BDA}$ host: $2 \%$ Flu-DPAN. $20 \mathrm{~nm}$ ) $/$ tris(8-quinolinolato) aluminum (Alq3, $40 \mathrm{~nm}) /(\mathrm{LiF} .1 \mathrm{~nm}) / \mathrm{Al}$. In this structure, ITO and $\mathrm{Al}$ are the anode and cathode, respectively. The stack of organic layers consists of DNTPD as the hole injection layer (HL), NPD as the hole transport layer (HTL), (BDA host: $2 \%$ FluDPAN) or (BDA host: $2 \%$ Ph-DPAN) as the emitting layer (EML), respectively, $\mathrm{Alq}_{\mathrm{s}}$ as the electron transport layer (ETL) and $\mathrm{LiF}$ as the electron injection layer (EIL). The threshold voltage charactenstics of the devices with (BDA host: $2 \%$ Flu-DPAN) was $6.5 \mathrm{~V}$. Figure 6 shows the current-voltageluminance (I-V-L) characteristics of devices. The maximum lununance values of $7000 \mathrm{~cd} / \mathrm{m}^{2}$ at $100 \mathrm{~mA} / \mathrm{cm}^{2}$ for BDA host: $2 \%$ Flu-DPAN was observed whlle the device for FluDPAN as emitting layer stared the emission at around $9.3 \mathrm{~V}$ and reached a luminescence of $4500 \mathrm{~cd} / \mathrm{m}^{2}$ at $100 \mathrm{~mA} / \mathrm{cm}^{2}$. 14 As shown in Figure 6 . the current density of device for BDA host: $2 \%$ Flu-DPAN as emitting layer decrease at the same voltage compared with that of device for Flu-DPAN as enutting layer. reflecting important feature of guest/host system. namely charge trapping mechanism. The maximum
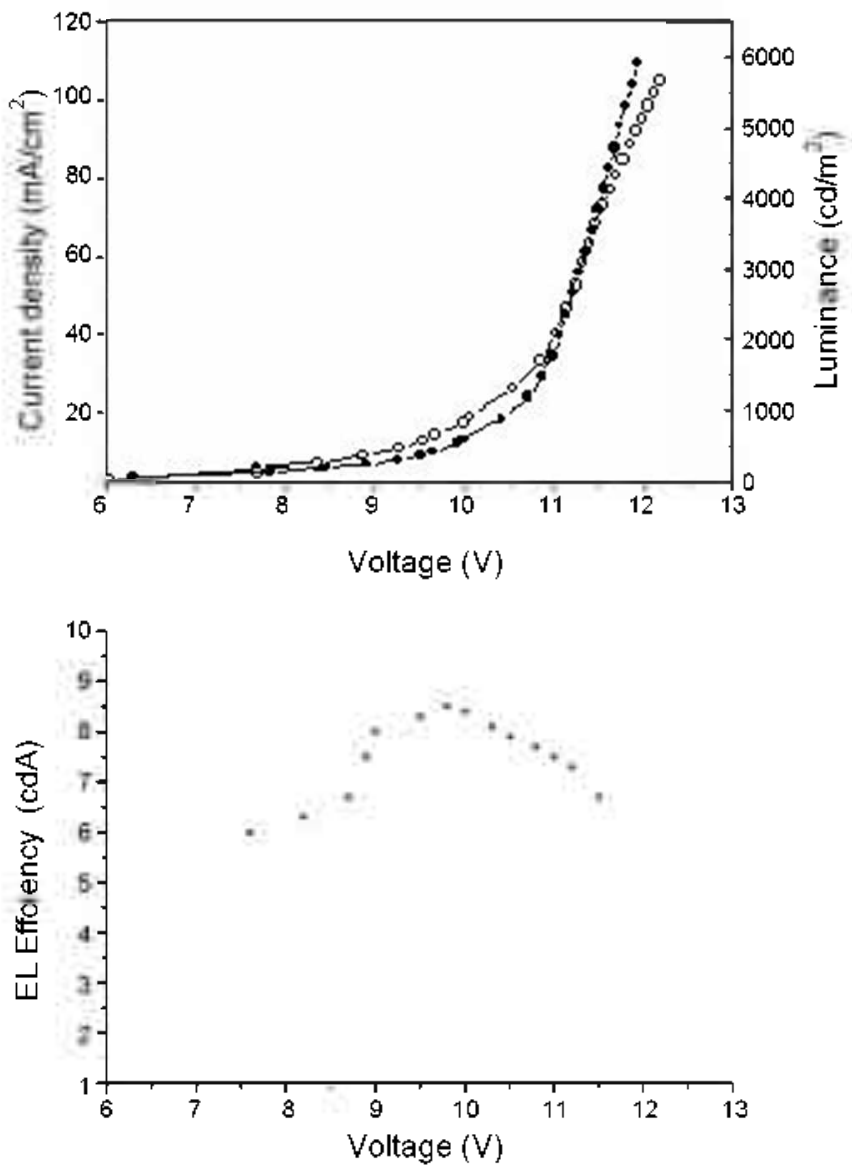

Figure 6. The current-voltage-lumnnance (I-V-L) charactenstics of indium tin oxide (ITO)/(DNTPD, $15 \mathrm{~nm}) /(\mathrm{NPD}, 20 \mathrm{~nm})(\mathrm{BDA}$ host: $2 \%$ Flu-DPAN, $20 \mathrm{~nm}$ ) /tris (8-quinolinolato) aluminum (Alq3, 40 nm $\mathrm{y} / \mathrm{LiF}(\mathrm{lnm}) / \mathrm{Al}$. 


\section{Color Coordinate(CIE) \& Flu-DPAN - Flu-DPAN-Host}

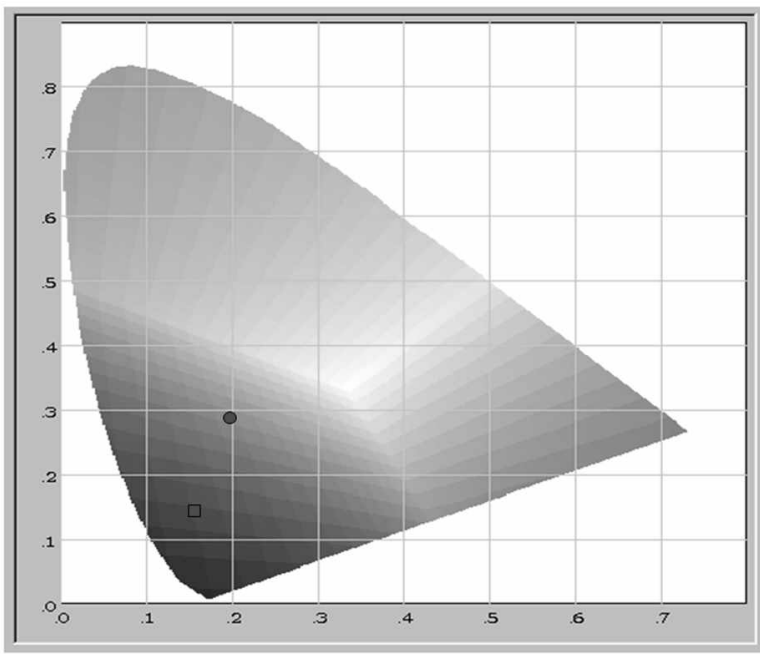

Figure 7. The commission Internationale de L'Eclairage (CIE) coordinates of device for BDA host: $2 \%$ Flu-DPAN and the device for Flu-DPAN.

current efficiency of BDA host: $2 \%$ Flu-DPAN as emitting layer is $8 \mathrm{~cd} / \mathrm{A}$ while the maximum current efficiency of Flu-DPAN as emitting layer is $5.8 \mathrm{~cd} / \mathrm{A}$

It is generally known that the enhancement of device efficiency is not significant for blue emitting devices owing to the poor spectral overlap for Foster energy transfer between a blue host emitter and blue guest. although the efficiency of green or red emitting devices significantly increases by doping dyes into host emitting layers. ${ }^{6}$ In this respect. BDA is an excellent blue host materials because there is effective energy transfer from BDA to the blue dopant due to the closed match of emission spectrum of BDA as host and absorption spectnum of Flu-DPAN as guest. leading high EL efficiency. In addition, the hole trapping followed by the direct recombination with electrons at the guest sites could additionally contribute to the enhanced EL efficiency.

The electroluminescence spectrum of device for BDA host: $2 \%$ Flu-DPAN as emitting layer is almost consistent with the PL spectrum of Flu-DPAN. This result indicates that the light emission originated from the Flu-DPAN dopant. rather than from the blue host. BDA. The commission Internationale de L'Eclairage (CIE) coordinates of device for BDA host: $2 \%$ Flu-DPAN and the device for Flu-DPAN was compared in Figure 7 . The color purity is improved to $(0.15,0.15)$. (Figure 6 )

In conclusion. we șynthesized new wide-gap blue host material having anthracene main unit because of the compatible ability with reported anthracene blue guest and developed efficient blue light emitting diode by using this host material with the blue fluorescent dopant Flu-DPAN. It has been revealed that the Foster energy transfer and charge trapping process both worked in this doping system of wide gap blue host: $2 \%$ Flu-DPAN. The device for blue host: $2 \%$ Flu-DPAN as emitting layer demonstrates bright blue emission with ligh color purity [CIE coordinates $=(0.15 .015)]$ and a high efficiency of $8 \mathrm{~cd} / \mathrm{A}$. The new designed $\mathrm{BDA}$ is a very efficient blue host material because it has effective spectral overlap with the blue guest, Flu-DPAN, as well as wider band gap than that of blue guest. Flu-DPAN. From the results. it is expected that the new synthesized BDA can be efficient blue host material for anthracene-based blue guest materials

Aclanowledgments. This research was financially supported by the Ministry of Know ledge Economy (MKE) and Korea Industrial Teclunology Foundation (KOTEF) through the Human Resource Training Project for Strategic Technology and by Strategic Teclunology Under Ministry of Knowledge Economy of Korea.

\section{References}

1. (a) Tang, C. W.: Van Slyke, S. A. Appl Phys. Lett. 1987, 51, 913. (b) Tullo, A. H. Chent. Eng. New's 2000, 78 (June 26), 20. (c) Tullo, A. H. Chem. Engr. News 2001, 79 (Nov 19), 49.

2. Van Slyke, S. A.; Chen, C. H.; Tang, C. W. Appl. Phys, Len. $1996,69.2160$

3. Adachi, C : Tsutsui, T.; Saito, S .Appl Plnus Letr. 1990, 57,531

4. Hung, L. S.; Tang, C. W.; Masson, M. G. Appl. Pltys. Lett. 1997. 70,152

5. (a) Park, J. W.; Kim, Y. H.; Jung, S. Y; Bveon, K. N.; Tann, S. H.; Lee, S. K.: Shin, S. C.; Kwon, S. K. Thin Solid Films 2008, 516 , 8381. (b) Kim, Y. H.: Shin, D. C.: Kim, S. H.: Ko, C. H.: Yu, H. S.: Chae, Y. S.; Kwon, S. K. Adv Mater: 2001, 13, 1690 . (c) Kim, Y. H.; Teong, H. C.; Kim, S. H.; Yang, K. Y.; Kwon, S. K. $A d$ : Func, Hoter: 2005, 15, 1799. (c) Kim, Y. H; Kim, H. S.; Alur, J. H.: Kim, S. H.: Kwon, S. K. J of Non. Opt. Phy \& M Iat. 2004, 13, 649. (d) Kim, I. U.: Lee, H. B.: Shin, I. S.: Kim, Y. H.: Ioe, Y. K: Oh, H. Y.: Park, C. G.; Kwon, S. K. Swmh. 1/et. 2005, 150, 27. (e) Kim, Y. H.; Lee, S. T. Jung, S. Y.; Bveon, K. N.; Kim, J ; Shin, S. C.; Kwon, S. K. Bull. Korean Chent. Soc. 2008, $28,443$.

6. Tang, C. W; Vanslyke, S. A.; Chen, C. H. J. Appl. Phys. 1989 , 65,3610

7. (a) Jeon, S. O.: Lee. H. S.: Jeon, Y. M.: Kim, J. W.: Lee, C. W.; Gong, M. S. 2009, 30, 863. (b) Sato, Y. Senticond. Sentintet. 2000, 64, 209. (c) Rajeswaren, G.; Ito, M.; Boroson, M.; Barry, S.; Hatwar, T. K.; Kahen, K. B.; Yoneda, Y.; Yokoyama, R.; Yamada, T:; Komiya, N.: Kanno, H.: Takahashi, H. SID 2000 Dig. 2000, 40, 1. (d) O connor, S. T. M.; Towns, C. R.; O'Dell, R.; Burroughes, J. H. Proc. SPIE-Int. Soc. Opt. Eng. 2001, $1105,9$.

8. Shi, J. M.; Tang, C. W. Appl. Phys. Lett. 2002, 80, 3201.

9. Chen, C. H.; Tang, C. W.; Shi, T.; Klubeck, K. F. Thin Solid Filnts $2000,363,327$.

10. He, F.; Tian, L.: Xie, W.; Li, M.; Gao, Q.; Hanif, M.: Zhang, Y:; Cheng. G.; Yang. B.: Ma. Y.: Liu, S.; Shen, J. J. Phus. Chem. C 2008, 112,12024 .

11. Lee, M. T; Chen, H. H.; Liao, C. H.; Tsai, C. H; Chen, C. H. 2004, 85,3301

12. Baldo, M. A.; Forrest, S. R. Phus. Rev. B 2000, 62, 10958.

13. Slooff, L. H.; Polman, A.; Caciallu, F.; Friend, R. H.: Hebbink, G. A.; van Veggel, F.; Reinhoudt, D. N. Appl. Phys. Leth. 2001, 78,2122 .

14. Jo, W. J.; Kim, K. H.; No, H. C.; Shin, D. Y.; Oh, S. J.; Son, J. W.; Kim, Y. H.; Cho, Y. K.: Lee, K. H.: Oh, H. Y.; Kwon, S. K. Smth. Met. 2009, 159, 1359

15. Jones, S.: Atherton, T. C. C. Swth Commm 2001, 31, 1799 